\title{
DETERMINATION OF EMPLOYEE JOB SATISFACTION PT BANK SYARIAH MANDIRI
}

\author{
irawidya $^{1}$, Arbanur Rasyid ${ }^{2}$, Muhammad Wandisyah R Hutagalung ${ }^{3}$, M. Fauzan ${ }^{4}$ \\ ${ }^{1}$ IAIN Padangsidimpuan (Perbankan Syariah, FEBI, IAIN Padangsidimpuan) \\ ${ }^{2}$ IAIN Padangsidimpuan (Hukum Syariah, FEBI, IAIN Padangsidimpuan) \\ ${ }^{3}$ IAIN Padangsidimpuan (Perbankan Syariah, FEBI, IAIN Padangsidimpuan) \\ ${ }^{4}$ IAIN Padangsidimpuan (Perbankan Syariah, FEBI, IAIN Padangsidimpuan) \\ irawidya@gmail.com¹, arbanurrasyid@iain-padangsidimpuan.ac.id ${ }^{2}$, muhammadwandisyah@iain- \\ padangsidimpuan.ac.id ${ }^{3}$, mfauzan@iain-padangsidimpuan.ac.id ${ }^{4}$
}

\begin{abstract}
ABSTRAK
Fluktuasi yang terjadi pada jumlah karyawan di PT Bank Syariah Mandiri Kantor Cabang Pembantu Gunung Tua, yang mana ini mengindikasikan adanya ketidakpuasan pada karyawan. Fluktuasi yang terjadi diakibatkan beberapa karyawan yang mengajukan resign dengan beberapa alasan serta pemberhentian karyawan akibat tidak tercapainya target.Rumusan masalah dalam penelitian ini adalah apakah pengaruh lingkungan kerja, kompetensi, dan pengembangan karir memiliki pengaruh terhadap kepuasan kerja karyawan.Tujuannya adalah untuk mengetahui apakah ada pengaruh ketiga variabel tersebut terhadap kepuasan kerja karyawan pada PT Bank Syariah Mandiri Kantor Cabang Pembantu Gunung Tua. Penelitian ini adalah penelitian kuantitatif dengan pengambilan sampel menggunakan sampel jenuh dengan jumlah sampel 17. Teknik pengumpulan data dengan studi kepustakaan, wawancara, dokumentasi dan angket.Teknik analisis data meliputi uji instrumen (uji validitas, uji reliabilitas), uji asumsi klasik (uji normalitas, uji multikolinearitas, uji heteroskedastisitas), analisis regresi linier berganda, uji hipotesis (uji koefisien determinasi $\left(R^{2}\right)$, uji $t$, uji F). Untuk mempermudah proses analisis data penelitian ini maka dibantu dengan program SPSS versi 23. Hasil uji t menunjukkan bahwa tidak terdapat pengaruh lingkungan kerja terhadap kepuasan kerja karyawan, tidak terdapat pegaruh antara kompetensi terhadap kepuasan kerja karyawan, dan terdapat pengaruh antara pengembangan karir terhadap kepuasan kerja karyawan.Secara simultan terdapat pengaruh antara lingkungan kerja, kompetensi, dan pengembangan karir terhadap kepuasan kerja karyawan.

Kata Kunci: Kepuasan Kerja, Kompetensi, Lingkungan Kerja, Pengembangan Karir
\end{abstract}

\section{ABSTRACT}

Fluctuations that occur in the number of employees at PT Bank Syariah Mandiri Gunung Tua Sub-Branch Office, which indicates employee dissatisfaction. The fluctuation that occurred was caused by several employees who applied for resignation for several reasons as well as employee dismissal due to not achieving the target. The formulation of the problem in this study is whether the influence of work environment, competence, and career development has an influence on employee job satisfaction. The aim is to determine whether there is an influence of these three variables on employee job satisfaction at PT Bank Syariah Mandiri Gunung Tua Sub-Branch Office. This research is a quantitative study with sampling using saturated samples with a sample size of 17 . The data collection technique uses 
literature study, interviews, documentation and questionnaires. Data analysis techniques include instrument test (validity test, reliability test), classic assumption test (normality test, multicollinearity test, heteroscedasticity test), multiple linear regression analysis, hypothesis testing (determination coefficient test $\left(R^{2}\right), t$ test, $F$ test). To simplify the data analysis process, this research was assisted by the SPSS version 23 program. The results of the t test showed that there was no influence of the work environment on employee job satisfaction, there was no influence between competence on employee job satisfaction, and there was an influence between career development on employee job satisfaction. Simultaneously there is an influence between work environment, competence, and career development on employee job satisfaction.

Keywords: Job Satisfaction, Competence, Work Environment, Career Development

\section{A. PENDAHULUAN}

Kepuasan kerja adalah sikap seorang karyawan terhadap pekerjaan yang diberikan kepadanya. Dimana kepuasan kerja ini berhubungan imbalan yang diterima dalam kerja, kerja sama antar karyawan, situasi kerja, dan hal-hal yang menyangkut faktor fisik dan psikologis. Sikap seorang karyawan terhadap pekerjaannya merupakan sejumlahsikap khusus individu terhadap hubungan sosial individu, penyesuaian diri individu, dan faktor-faktor dalam pekerjaan sehingga menimbulkan sikap umum individu terhadap pekerjaan yang dihadapi oleh seorang karyawan.(Edy Sutrisno, 2009:74).

Berdasarkan data yang diperoleh oleh peneliti yaitu jumlah keseluruhan karyawan pada PT Bank Syariah Mandiri Kantor Cabang Pembantu Gunung Tua, ditemukan bahwa kepuasan karyawan belum sepenuhnya terpenuhi.Hal ini ditunjukkan dari jumlah seluruh karyawan yang menggambarkanfluktuasi.Di bawah ini berupa tabel data jumlah karyawan pada PT Bank
Syariah Mandiri Kantor Cabang Pembantu Gunung Tua.

Tabel I.1

Data Jumlah Karyawan di PT Bank Syariah Mandiri

Kantor Cabang Pembantu Gunung Tua Sumber: BSM KCP Gunung Tua

\begin{tabular}{|c|c|c|}
\hline No & Tahun & $\begin{array}{c}\text { Jumlah Seluruh Karyawan } \\
\text { (Jiwa) }\end{array}$ \\
\hline 1. & 2013 & 33 \\
\hline 2. & 2014 & 34 \\
\hline 3. & 2015 & 32 \\
\hline 4. & 2016 & 18 \\
\hline 5. & 2017 & 20 \\
\hline 6. & 2018 & 22 \\
\hline 7. & 2019 & 23 \\
\hline 8. & 2020 & 17 \\
\hline
\end{tabular}

Berdasarkan tabel diatas dapat dilihat bahwa data jumlah karyawan di PT Bank Syariah Mandiri Kantor Cabang Pembantu Gunung Tua mengalami fluktuasi.Dimana dari tahun 2013 hingga tahun 2014 jumlah karyawan mengalami kenaikan.Kemudian dari tahun 2014 hingga tahun 2016 mengalami penurunan yang sangat drastis.Pada tahun 2016 hingga tahun 2019 jumlah karyawan mengalami kenaikan.Kemudian pada tahun 2020 jumlah 
Ira Widya ${ }^{1}$, Arbanur Rasyid ${ }^{2}$, Muhammad Wandisyah R Hutagalung ${ }^{3}$, M. Fauzan ${ }^{4}$

karyawan mengalami penurunan kembali, yang mana ini dapat mengindikasikan adanya ketidakpuasan karyawan di PT Bank Syariah Mandiri Kantor Cabang Pembantu Gunung Tua.

Fluktuasi yang terjadi pada data jumlah karyawan pada PT Bank Syariah Mandiri Kantor Cabang Pembantu Gunung Tua diakibatkan beberapa karyawan diketahui mengajukan resign. Pengajuan resign yang dilakukan karyawan diakibakan beberapa faktor yaitu karena telah menikah, pindah domisili dan juga beban kerja yang diberikan tidak sesuai dengan keahlian karyawan. Adapun sebagian karyawan diberhentikan oleh perusahaan diakibatkan tidak tercapainya target yang telah ditentukan oleh perusahaan.

Oleh karena itu, peneliti melakukan wawancara dengan salah seorang karyawan pada PT Bank Syariah Mandiri Kantor Cabang Pembantu Gunung Tua. Dalam wawancara tersebut, Bapak Amir Hamzah Harahap selaku Micro Financing Analyst mengatakan:Hubungan antara karyawan dan pimpinan terjalin dengan baik, dengan sistem menemui langsung karyawan saat bekerja yang berbeda dengan pimpinan sebelumnya dimana setiap urusan kerja, karyawan harus menemui pimpinan langsung ke ruangannya. Sama halnya juga hubungan antara karyawan atau rekan kerja yang terjalin dengan baik. Dari sistem pemberian gaji telah sesuai dengan tanggungjawab yang telah dibebankan kepada karyawan.Namun, keterampilan ataupun kemampuan yang dimiliki karyawan untuk
POINT Vol. 2, No. 1, Jul 2021 jabatan sekarang masih terbilang kurang. Dari sistem pengembangan karirnya, bank menerapkan training banking setiap tahunnya untuk mengembangkan kemampuan para karyawannya. Dimana training banking yang diterapkan sesuai dengan posisi yang diduduki oleh karyawan, yang dilaksanakan selama 15 hari kerja untuk karyawan tetap. Bagi karyawan yang akan menaiki jabatan akan mengikuti ujian dengan 3 tahap yaitu ujian online, diberangkatkan ke Jakarta selama 2 minggu, serta melakukan ujian penelitian setelah kembali ke bank. Kemudian dari prestasi yang telah dicapai selama bekerja, Pak Amir telah di promosikan dari jabatan yang sebelumnya sebagai Marketing Support menjadi Micro Financing Sales.(Amir Hamzah Harahap, Micro Financing Analyst, 20 April 2020).

Berdasarkan pendapat Keith Davis, dkk., menyatakan bahwa Sesuatu yang berhubungan dengan kondisi dirinya maupun pekerjaannyayang timbul dari perasaan diri pegawai merupakan kepuasaan kerja. Adapun yang menyangkut dengan kondisi dirinya antara lain, pendidikan, kemampuan, kondisi kesehatan, umur. Sedangkan yang berhubungan dengan pekerjaan meliputi mutu pengawasan, struktur organisasi perusahaan, jenis pekerjaan, penempatan kerja, hubungan antar karyawan, kesempatan pengembangan karir, upah yang diterima. 


\section{B. METODE}

Adapun yang menjadi lokasi penelitian ini adalah di PT Bank Syariah Mandiri Kantor Cabang Pembantu Gunung Tua. Sedangkan waktu penelitian ini mulai dilaksanakan mulai bulan Februari 2020 sampai dengan Januari 2021. Jenis penelitian ini adalah penelitian kuantitatif yaitu penelitian guna menggambarkan ataupun menguraikan suatu keadaan menggunakan data berupa angka sebagai alat menganalisis keterangan tentang apa yang ingin diketahui. (Sandu Siyoto dan Ali Sodik, 2015:9)

Adapun populasi dalam penelitian ini adalah sebanyak 17 orang karyawan yang berada di PT Bank Syariah Mandiri Kantor Cabang Pembantu Gunung Tua. Teknik pengambilan sampel yaitu menggunakan sampel jenuh. Sampel jenuh adalah suatu teknik penentuan sampel jika seluruh anggota populasi diambil sebagai sampel. (Sugiyono, 2014:116). Adapun sampel dalam penelitian yaitu 17 orang karyawan yang berada di PT Bank Syariah Mandiri Kantor Cabang Pembantu Gunung Tua. Adapun instrumen pengumpulan data dalam penelitian ini adalah studi kepustakaan, wawancara, dokumentasi, dan angket.

\section{HASIL DAN PEMBAHASAN}

Uji Validitas

Uji validitas menunjukkan apakah ada pernyataan-pernyataan pada kuesioner yang harus dibuang atau diganti karena tidak relevan. Pengujian validitas dilakukan dengan membandingkan $\quad r$ tabel product moment.(Syofian Siregar, 2012:162)

Tabel IV.3

Hasil Uji Validitas Variabel Lingkungan Kerja (X1)

\begin{tabular}{|c|c|c|c|}
\hline $\begin{array}{c}\text { Item } \\
\text { Pernyataan }\end{array}$ & $r_{\text {hitung }}$ & $r_{\text {tabel }}$ & Keterangan \\
\hline 1 & 0,662 & \multirow{8}{*}{$\begin{array}{c}\text { Instrumen } \\
\text { valid jika } \\
r_{\text {hitung }}> \\
r_{\text {tabel }} \\
\text { dengan df } \\
=n-3= \\
17-3=14 \\
\text { pada taraf } \\
\text { signifikan } \\
5 \% \\
\text { sehingga } \\
\text { diperoleh } \\
r_{\text {tabel }}= \\
0,4973\end{array}$} & Valid \\
\hline 2 & 0,809 & & Valid \\
\hline 3 & 0,734 & & Valid \\
\hline 4 & 0,586 & & Valid \\
\hline 5 & 0,626 & & Valid \\
\hline 6 & 0,821 & & Valid \\
\hline 7 & 0,592 & & Valid \\
\hline 8 & 0,588 & & Valid \\
\hline
\end{tabular}

Sumber: Data primer diolah, 2020

Berdasarkan hasil uji validitas pada variabel lingkungan kerja diatas menunjukkan bahwa dari masing-masing item pernyataan yang telah disusun oleh peneliti memiliki nilai rhitung > rtabel, sehingga dapat disimpulkan bahwa seluruh pernyataan yang dijadikan adalah valid.

Tabel IV.4

Hasil Uji Validitas Variabel Kompetensi (X2)

\begin{tabular}{|c|c|c|c|}
\hline $\begin{array}{c}\text { Item } \\
\text { Pernyataan }\end{array}$ & $r_{\text {hitung }}$ & $r_{\text {tabel }}$ & Keterangan \\
\hline 1 & 0,670 & \multirow{6}{*}{$\begin{array}{c}\text { Instrumen } \\
\text { valid jika } \\
\mathrm{r}_{\text {hitung }}>\mathrm{r}_{\text {tabel }} \\
\text { dengan df } \\
=\mathrm{n}-3=17- \\
3=14 \text { pada } \\
\text { taraf } \\
\text { signifikan } \\
5 \% \\
\text { sehingga } \\
\text { diperoleh }\end{array}$} & Valid \\
\hline 2 & 0,809 & & Valid \\
\hline 3 & 0,670 & & Valid \\
\hline 4 & 0,826 & & Valid \\
\hline 5 & 0,656 & & Valid \\
\hline 6 & 0,734 & & Valid \\
\hline
\end{tabular}


Ira Widya ${ }^{1}$, Arbanur Rasyid ${ }^{2}$, Muhammad Wandisyah R Hutagalung ${ }^{3}$, M. Fauzan ${ }^{4}$

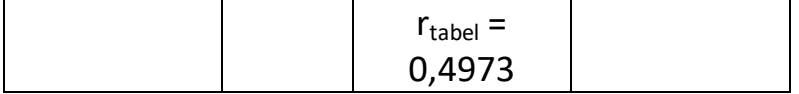

Sumber: Data primer diolah, 2020

Berdasarkan hasil uji validitas pada variabel kompetensi diatas menunjukkan bahwa dari masing-masing item pernyataan yang telah disusun oleh peneliti memiliki nilai rhitung > rtabel, sehingga dapat disimpulkan bahwa seluruh pernyataan yang dijadikan adalah valid.

Tabel IV.5

Hasil Uji Validitas Variabel Pengembangan

Karir (X3)

\begin{tabular}{|c|c|c|c|}
\hline $\begin{array}{c}\text { Item } \\
\text { Pernyataan }\end{array}$ & $r_{\text {hitung }}$ & $r_{\text {tabel }}$ & Keterangan \\
\hline 1 & 0,884 & \multirow{8}{*}{$\begin{array}{c}\text { Instrumen } \\
\text { valid jika } \\
r_{\text {hitung }}> \\
r_{\text {tabel }} \\
\text { dengan df } \\
=n-3= \\
17-3=14 \\
\text { pada taraf } \\
\text { signifikan } \\
5 \% \\
\text { sehingga } \\
\text { diperoleh } \\
r_{\text {tabel }}= \\
0,4973\end{array}$} & Valid \\
\hline 2 & 0,777 & & Valid \\
\hline 3 & 0,829 & & Valid \\
\hline 4 & 0,576 & & Valid \\
\hline 5 & 0,821 & & Valid \\
\hline 6 & 0,764 & & Valid \\
\hline 7 & 0,717 & & Valid \\
\hline 8 & 0,707 & & Valid \\
\hline
\end{tabular}

Sumber: Data primer diolah, 2020

Berdasarkan hasil uji validitas pada variabel pengembangan karir diatas menunjukkan bahwa dari masing-masing item pernyataan yang telah disusun oleh peneliti memiliki nilai $r_{\text {hitung }}>r_{\text {tabel, }}$, sehingga dapat disimpulkan bahwa seluruh pernyataan yang dijadikan adalah valid.

Tabel IV.6

Hasil Uji Variabel Kepuasan Kerja (Y)
POINT Vol. 2, No. 1, Jul 2021

\begin{tabular}{|c|c|c|c|}
\hline $\begin{array}{c}\text { Item } \\
\text { Pernyataan }\end{array}$ & $r_{\text {hitung }}$ & $r_{\text {tabel }}$ & Keterangan \\
\hline 1 & 0,766 & \multirow{9}{*}{$\begin{array}{c}\text { Instrumen } \\
\text { valid jika } \\
r_{\text {hitung }}> \\
r_{\text {tabel }} \\
\text { dengan df } \\
=n-3= \\
17-3=14 \\
\text { pada taraf } \\
\text { signifikan } \\
5 \% \\
\text { sehingga } \\
\text { diperoleh } \\
r_{\text {tabel }}= \\
0,4973\end{array}$} & Valid \\
\hline 2 & 0,922 & & Valid \\
\hline 3 & 0,580 & & Valid \\
\hline 4 & 0,516 & & Valid \\
\hline 5 & 0,620 & & Valid \\
\hline 6 & 0,613 & & Valid \\
\hline 7 & 0,720 & & Valid \\
\hline 8 & 0,767 & & Valid \\
\hline 9 & 0,581 & & Valid \\
\hline
\end{tabular}

Sumber: Data primer diolah, 2020

Berdasarkan hasil uji validitas pada variabel kepuasan kerja diatas menunjukkan bahwa dari masing-masing item pernyataan yang telah disusun oleh peneliti memiliki nilai rhitung > rtabel, sehingga dapat disimpulkan bahwa seluruh pernyataan yang dijadikan adalah valid.

Uji Reliabilitas

Suatu konstruk atau variabel dapat dikatatan reliable jika nilai cronbach alpha> 0,60 . Jika nilai cronbach alpha $<0,60$ maka pernyataan-pernyataan yang digunakan untuk variabel tersebut tidak realiable.

Tabel IV.7

Hasil Uji Reliabilitas

\begin{tabular}{|l|c|c|}
\hline Variabel & $\begin{array}{l}\text { Cronbach's } \\
\text { Alpha }\end{array}$ & N of Item \\
\hline Lingkungan Kerja (X1) & 0,795 & 8 \\
\hline Kompetensi (X2) & 0,816 & 6 \\
\hline $\begin{array}{l}\text { Pengembangan Karir } \\
\text { (X3) }\end{array}$ & 0,889 & 8 \\
\hline
\end{tabular}




\begin{tabular}{|l|l|l|}
\hline Kepuasan Kerja (Y) & 0,854 & 9 \\
\hline
\end{tabular}

Sumber: Data primer diolah, 2020

Berdasarkan hasil uji diatas menunjukkan bahwa Cronbach's Alpha untuk variabel lingkungan kerja adalah $0,795>0,60$ sehingga variabel lingkungan kerja dapat dikatakan reliable. Kemudian variabel kompetensi adalah $0,816>0,60$ sehingga variabel kompetensi dapat dikatakan reliable. Selanjutnya variabel pengembangan karir adalah 0,889> 0,60 sehingga variabel pengembangan karir dapat dikatakan reliable. Kemudian variabel kepuasan kerja adalah 0,854 $>0,60$ sehingga variabel kepuasan kerja dapat dikatakan reliable.

Uji Normalitas

Uji normalitas adalah uji untuk menunjukkan apakah populasi terdistribusi normal atau tidak. Pada penelitian ini digunakanuji one sample kolmogrov-smirnov dengan menggunakan taraf signifikan lel ". besar dari $10 \%$ atau 0,1 .

Tabel IV.8 Hasil UjiNormalitas

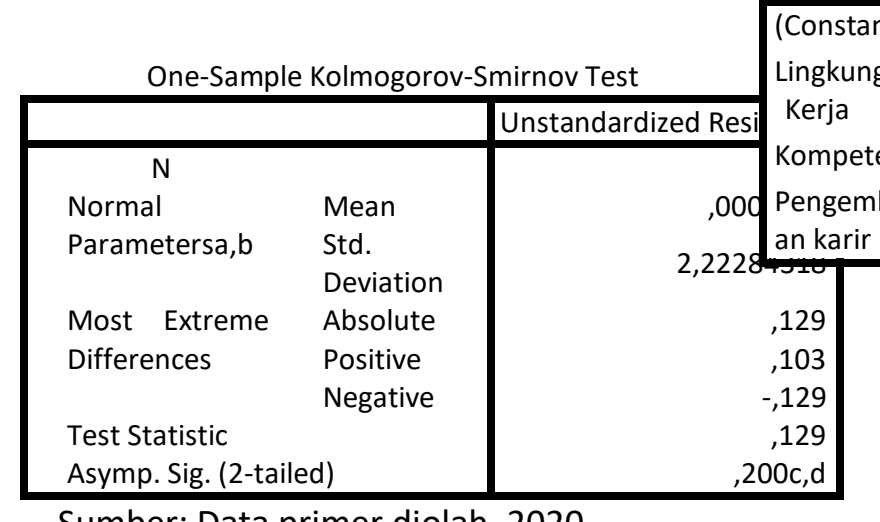

Sumber: Data primer diolah, 2020
Berdasarkan tabel di atas dilihat dari hasil uji normalitas bahwa nilai signifikan (asymp.Sig 2- tailed) sebesar 0,200. Nilai tersebut lebih besar dari nilai signifikan 0,10 $(0,200>0,10)$. Jadi dapat disimpulkan bahwa data tersebut terdistribusi normal

Uji Multikolinearitas

Uji multikolinearitas adalah uji untuk menunjukkan ada atau tidaknya korelasi yang tinggi antara variabel-variabel independen dalam suatu model regresi linear berganda.Jika nilai tolerance lebih kecil dari 0,1maka terjadi multikolinearitas pada data yang diuji. Multikolinearitas dapat dilihat dari VIF (Varience Inflation Factor). Jika nilai VIF $>10$ maka artinya terjadi multikolinearitas terhadap data yang diuji.

Tabel IV.9

Hasil Uji Multikolinearitas
Coefficientsa

\begin{tabular}{|c|c|c|c|c|c|c|}
\hline \multicolumn{2}{|c|}{$\begin{array}{l}\text { Unstandardize } \\
\text { d Coefficients }\end{array}$} & $\begin{array}{l}\text { ed } \\
\text { Coefficie } \\
\text { nts }\end{array}$ & & & \multicolumn{2}{|c|}{$\begin{array}{r}\text { Collinearity } \\
\text { Statistics } \\
\end{array}$} \\
\hline & $\begin{array}{l}\text { Std. } \\
\text { Error }\end{array}$ & Beta & $\mathrm{t}$ & Sig. & Tolerance & VIF \\
\hline 1,660 & 9,231 & & 180 &, 860 & & \\
\hline 092 & ,258 & 069 & 355 &, 728 &, 623 & 1,604 \\
\hline 140 & 478 & 070, & 293 & ,774 & ,405 & 2,467 \\
\hline 827 & 214 & 770 & 3,860 &, 002 &, 587 & 1,703 \\
\hline D & & & 20 & & & \\
\hline
\end{tabular}

bahwa nilai VIF dari variabel lingkungan kerja sebesar $1,604<10$ sedangkan variabel kompetensi sebesar 2,467 < 10 dan variabel 
Ira Widya ${ }^{1}$, Arbanur Rasyid ${ }^{2}$, Muhammad Wandisyah R Hutagalung ${ }^{3}$, M. Fauzan ${ }^{4}$

POINT Vol. 2, No. 1, Jul 2021

pengembangan karir sebesar $1,703<10$. Maka

tertentu. Titik-titik menyebar di atas dan di

dapat disimpulkan bahwa tidak terjadi bawah angka 0 pada sumbu Y. Maka dapat multikolinearitas antara variabel independent. Sementara nilai tolerance dari variabel lingkungan kerja sebesar $0,623>0,1$ sedangkan variabel kompetensi sebesar 0,405 $>0,1$ dan variabel pengembangan karir sebesar 0,587 > 0,1 . Maka dapat disimpulkan bahwa nilai tolerance dari ketiga variabel independent lebih besar dari 0,1 sehingga tidak terjadi multikolinearitas antara variabel independent.

Uji Heteroskedastisitas

Suatu model regresi dikatakan tidak terjadi heteroskedastisitas apabila titik-titik pada scatterplot regresi tidak membentuk pola tertentu, seperti menyebar di atas dan di bawah angka 0 pada sumbu $Y$, berikut hasil uji heteroskedastisitas:

Gambar IV. 2

Hasil Uji Heteroskedastisitas

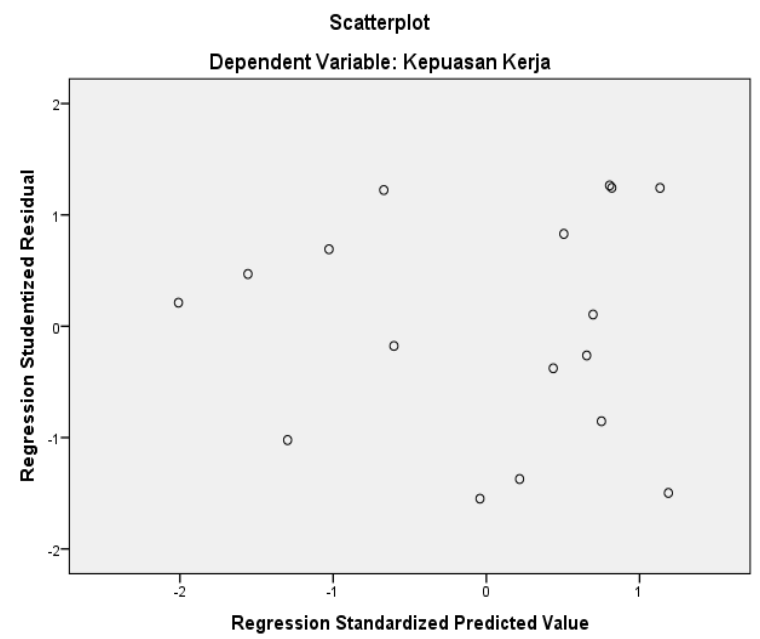

Sumber: Data Primer diolah, 2020

Dari output data di atas dapat dilihat bahwa titik-titik tidak membentuk suatu pola

disimpulkan bahwa model regresi terbatas dari heteroskedastisitas.

Berdasarkan tabel di atas dapat disimpulkan bahwa Unstandardized Coefficients tabel maka persentase analisis regresi linier berganda dalam penelitian ini adalah:

$\mathrm{KK}=1,660+0,092 \mathrm{LK}+0,140 \mathrm{KP}+0,827+9,231$

Berdasarkan persamaan regresi diatas dapat diartikan bahwa:

1. Nilai konstanta ( $\alpha)$ sebesar1,660 menunjukkan bahwa jika lingkungan kerja, kompetensi dan pengembangan karir nilainya 0, maka kepuasan kerja sebesar 1,660 satuan.

2. Nilai koefisien variabel lingkungan kerja benilai positif sebesar 0,092 dapat diartikan bahwa setiap peningkatan lingkungan kerja sebesar 1 satuan, maka kepuasan kerja mengalami peningkatan sebesar 0,092 satuan dengan asumsi variabel independen lainnya nilainya tetap.

3. Nilai koefisien variabel kompetensi bernilai positif sebesar 0,140 dapat diartikan bahwa setiap peningkatan kompetensi sebesar 1 satuan, maka kepuasan kerja mengalami peningkatan sebesar 0,140 satuan dengan asumsi variabel independen lainnya nilainya tetap.

4. Nilai koefisien variabel pengembangan karir bernilai positif sebesar 0,827 dapat 
diartikan bahwa setiap peningkatan pengembangan karir sebesar 1 satuan, maka kepuasan kerja mengalami peningkatan sebesar 0,827 satuan dengan asumsi variabel independen lainnya nilainya tetap.

Uji Determinasi (R2)

Koefisien determinasi digunakan untuk mengetahui persentase sumbangan pengaruh variabel independen secara serentak terhadap variabel dependen. Semakin besar nilai R2 (mendekati 1), maka ketetapannya dikatakan semakin baik.

Tabel IV.12

Hasil Uji Determinasi

\begin{tabular}{|l|l|l|l|c|}
\hline \multirow{2}{*}{ Model } & & Rodel Summaryb \\
\hline &, $834 a$ &, 696 &, 626 & 2,466 \\
\hline
\end{tabular}

Sumber: Data primer diolah, 2020

Berdasarkan hasil uji diatas diperoleh nilai R2 (Adjusted R Square) sebesar 0,626 atau 63\%. Hal ini menunjukkan bahwa persentase pengaruh variabel lingkungan kerja, kompetensi dan pengembangan karir sebesar 63\%. Sedangkan sisanya sebesar 0,374 atau $37 \%$ dipengaruhi oleh variabel lain seperti kompensasi yang tidak dimasukkan dalam model penelitian ini.

Uji Koefisien Regresi Secara Parsial ( Uji t)

Pengujian untuk mengetahui apakah variabel lingkungan kerja, kompetensi dan pengembangan karir secara parsial berpengaruh signifikan terhadap variabel kepuasan kerja. Adapun hasil uji signifikan parsial adalah sebagai berikut:

Tabel IV.13

Hasil Uji Signifikansi Parsial (Uji t)

\begin{tabular}{|c|c|c|c|c|c|}
\hline \multirow[b]{3}{*}{ Model } & \multicolumn{4}{|c|}{ Coefficientsa } & \multirow[b]{3}{*}{ Sig. } \\
\hline & \multicolumn{2}{|c|}{$\begin{array}{c}\text { Unstandardized } \\
\text { Coefficients }\end{array}$} & $\begin{array}{l}\text { Standardize } \\
\text { d } \\
\text { Coefficient } \\
\text { s } \\
\end{array}$ & & \\
\hline & & d. Error & Beta & $\mathrm{T}$ & \\
\hline (Constant) & 1,660 & 9,231 & &, 180 &, 860 \\
\hline $\begin{array}{l}\text { Lingkungan } \\
\text { Kerja }\end{array}$ & ,092 &, 258 & ,069 & ,355 & ,728 \\
\hline Kompetensi & 140 &, 478 & ,070 & ,293 & ,774 \\
\hline $\begin{array}{l}\text { Pengembanga } \\
\mathrm{n} \text { karir }\end{array}$ & 827 &, 214 & 770 & 3,860 & ,002 \\
\hline
\end{tabular}

Sumber: Data primer diolah, 2020

Berdasarkan tabel diatas dihasilkan ttabel dengan rumus $\mathrm{df}=\mathrm{n}-\mathrm{k}-1$ ataupun 17-3-1 = 13 dengan signifikansi 0,01. Maka nilai ttabel sebesar 1,77093.

1. Berdasarkan tabel diatas diketahui variabel lingkungan kerja sebesar $0,355<1,77093$ maka HO diterima Ha ditolak. Jadi dapat disimpulkan bahwa lingkungan kerja tidak memiliki pengaruh terhadap kepuasan kerja karyawan pada PT Bank Syariah Mandiri Kantor Cabang Pembantu Gunung Tua.

2. Kemudian pada variabel kompetensi sebesar $0,293<1,77093$ sehingga $\mathrm{HO}$ diterima Ha ditolak. Jadi dapat disimpulkan bahwa kompetensi tidak memiliki pengaruh terhadap kepuasan kerja karyawan pada PT Bank Syariah Mandiri Kantor Cabang Pembantu Gunung Tua.

3. Sedangkan pada variabel pengembangan karir sebesar 3,860>1,77093 sehingga HO 
Ira Widya ${ }^{1}$, Arbanur Rasyid ${ }^{2}$, Muhammad Wandisyah R Hutagalung ${ }^{3}$, M. Fauzan ${ }^{4}$

ditolak Ha diterima. Jadi dapat disimpulkan

bahwa pengembangan karir memiliki pengaruh terhadap kepuasan kerja karyawan pada PT Bank Syariah Mandiri Kantor Cabang Pembantu Gunung Tua.

Uji Signifikan Simultan (Uji F)

Uji signifikan simultan (uji F) digunakan untuk mengetahui pengaruh secara simultan variabel lingkungan kerja, kompetensi dan pengembangan karir terhadap kepuasan kerja karyawan. Adapun hasil uji F dapat dilihat pada tabel dibawah ini:

Tabel IV.14

Hasil Uji Signifikan Simultan (Uji F)

\begin{tabular}{|l|r|r|r|l|l|}
\hline Model & $\begin{array}{c}\text { Sum of } \\
\text { Squares }\end{array}$ & Df & an Square & F & Sig. \\
\hline Regressio & 181,061 & 3 & 60,354 & 9,925 &, $001 \mathrm{~b}$ \\
$\mathrm{n}$ & 79,057 & 13 & 6,081 & & \\
Residual & 260,118 & 16 & & & \\
Total & & & \\
\hline
\end{tabular}

Sumber: Data primer diolah, 2020

Berdasarkan hasil diatas diketahui nilai Fhitung sebesar 9,925 dengan signifikan 0,05 dan $\mathrm{df}=\mathrm{n}-\mathrm{k}-1$ ataupun $17-3-1=13$ dan hasil Ftabel sebesar 3,41. Maka dapat diketahui bahwa Fhitung>Ftabel $(9,925>3,41)$ dan nilai signifikansi $0,001<0,01$ sehingga $\mathrm{HO}$ ditolak $\mathrm{Ha}$ diterima. Dimana artinya lingkungan kerja, kompetensi dan pengembangan karir memiliki pengaruh secara simultan terhadap kepuasan kerja karyawan pada PT Bank Syariah Mandiri Kantor Cabang Pembantu Gunung Tua.

Dari ketiga dimensi variabel X (lingkungan kerja, kompetensi, dan pengembangan karir)termasuk dimensi yang dipakai dalam
POINT Vol. 2, No. 1, Jul 2021 mengukur kepuasan kerja karyawan dikarenakan sama-sama kita ketahui ketiga dimensi ini sejalan untuk mengukur kepuasan kerja karyawan. Hasil uji F yang menjelaskan bahwa terdapat pengaruh secara simultan variabel lingkungan kerja, kompetensi, dan pengembangan karir terhadap kepuasan kerja karyawan. Hal ini berarti apabila ketiga dimensi variabel $\mathrm{X}$ terlaksana sesuai dengan prosedur yang semestinya dan berdasarkan harapan karyawan maka tingkat kepuasan karyawan juga akan meningkat, begitu juga sebaliknya.

\section{PENUTUP}

\section{Kesimpulan}

Berdasarkan hasil penelitian mengenai determinan kepuasan kerja karyawan pada PT Bank Syariah Mandiri yang dilakukan oleh peneliti di PT Bank Syariah Mandiri Kantor Cabang Pembantu Gunung Tua maka diperoleh kesimpulan sebagai berikut: secara parsial lingkungan kerja tidak memiliki pengaruh terhadap kepuasan kerja karyawan pada PT Bank Syariah Mandiri Kantor Cabang Pembantu Gunung Tua. Kompetensi tidak memiliki pengaruh terhadap kepuasan kerja karyawan pada PT Bank Syariah Mandiri Kantor Cabang Pembantu Gunung Tua. Sedangkan pengembangan karir memiliki pengaruh terhadap kepuasan kerja karyawan pada PT Bank Syariah Mandiri Kantor Cabang Pembantu Gunung Tua. Secara simultan lingkungan kerja, kompetensi, dan pengembangan karir memiliki pengaruh terhadap kepuasan kerja karyawan 
pada PT Bank Syariah Mandiri Kantor Cabang

Pembantu Gunung Tua.

\section{Saran}

Semoga adanya pengetahuan karyawan berikut pengembangan pengetahuan tentang perbankan syariah.

\section{DAFTAR PUSTAKA}

Abdul Nasser Hasibuan, The Effect of Profitability Ratios on Financial Distress in Islamic Commercial Banks in Indonesia.

Ali Hardana, Analisis Faktor-Faktor Yang Mempengaruhi Pendapatan Industri Kecil Di Kota Padangsidimpuan Dan Kabupaten Tapanuli Selatan.

Amir Hamzah Harahap, selaku Micro Financing Analyst, 20 April 2020.

Astadi Pangarso dan Vidi Ramadhyanti. 2015. “Pengaruh Lingkungan Kerja Non Fisik Terhadap Kepuasan Kerja Dosen Tetap Studi pada Fakultas Komunikasi dan Bisnis Universitas Telkom Bandung" Vol. 19 No. 1.

Aswadi Lubis. 2015. "Kepuasan Kerja dilihat dari Iklim Organisasi." Yurisprudentia Vol. 1, No. 1 (Juni).

- - . 2016. "Pengaruh Budaya Kerja dan Gaya Kepemimpinan Terhadap Kepuasan Kerja Pegawai Administrasi IAIN Padangsidimpuan." Jurnal Penelitian Ilmu-ilmu Sosial dan Keislaman Vol. 2 No. 2.

Cici Astrika. 2017. "Pengaruh Pegembangan Karir dan Lingkungan Kerja Terhadap Kepuasan Kerja Karyawan PT. Johan Sentosa Bangkinang" Vol. 4 No. 1 (Februari).
Departemen Agama RI. 2005. Al-Qur'an dan Terjemahnya. Bandung: Diponegoro.

Edy Sutrisno. 2009. Manajemen Sumber Daya Manusia. Jakarta: Kencana.

Ega Praja Rimata. 2014. "Pengaruh Komitmen Organisasi dan Motivasi Kerja Terhadap Kepuasan Kerja Karyawan PT. Pos Indonesia Yogyakarta." Program Studi ManajemenJurusan Manajemen akultas Ekonomi Universitas Ekonomi Universitas Negeri Yogyakarta.

Kenny Yulianto Kurniawan. 2015. "Pengaruh Pengembangan Karir dan Kompensasi Terhadap Kepuasan Kerja Karyawan di PT Parit Padang Global" Vol. 3 No. 2.

Mawadha Kestari Prety Diawati dan Hesty Sugesti. 2015. "Pengaruh Pengembangan Karir Terhadap Kepuasan Kerja Karyawan (Studi Kasus di PT Pelabuhan Indonesia II (Persero) Cabang Cirebon" Volume 1, No. 1 (Januari).

Mohammad Faisal Amir. 2015. Memahami Evaluasi Kinerja Karyawan: Konsep dan Penilaian Kinerja di Perusahaan. Jakarta: Mitra Wacana Media.

Nofinawati, Persepsi Pedagang Pasar Inpres Sadabuan Terhadap Baitul Mal Wat Tamwil (BMT) Insani Padangsidimpuan

Sandu Siyoto dan Ali Sodik. 2015. Dasar Metodologi Penelitian. Yogyakarta: Literasi Media Publishing.

Soekidjo Notoatmodjo. 2015. Pengembangan Sumber Daya Manusia. Jakarta: Rineka Cipta.

Sugiyono. 2014. Metode Penelitian Bisnis. Bandung: Alfabeta.

Syofian Siregar. 2012. Statistika Deskriftif Untuk Penelitian. Jakarta: Rajawali Pers. 